\title{
Observing fibrillar assemblies on scrapie-infected cells
}

\author{
Susanne Wegmann • Margit Miesbauer • \\ Konstanze F. Winklhofer • Jörg Tatzelt • \\ Daniel J. Muller
}

Received: 3 October 2007 /Revised: 8 December 2007 / Accepted: 10 December 2007 / Published online: 3 January 2008

(C) Springer-Verlag 2007

\begin{abstract}
The infectious agent in prion diseases is an aberrant-folded isoform of the cellular prion protein $\left(\operatorname{PrP}^{\mathrm{C}}\right)$. This scrapie-related prion protein $\left(\mathrm{PrP}^{\mathrm{Sc}}\right)$ has an increased $\beta$-sheet content, is detergent insoluble and proteinase $\mathrm{K}$ resistant, and accumulates in prion-infected organisms and cells. In vitro, $\operatorname{PrP}^{\mathrm{Sc}}$ self-aggregates into amyloid fibrils. However, there is no direct experimental proof for the occurrence of $\mathrm{PrP}^{\mathrm{Sc}}$-containing fibrils in vivo or in cell cultures. Applying atomic force microscopy (AFM) to scrapie-infected mouse neuroblastoma ( $\mathrm{ScN} 2 \mathrm{a})$ cells, we discovered growing patch-like assemblies of amyloid-like fibrillar structures on the cell surfaces. Immunofluorescence and AFM images showed heterogeneous accumulation and aggregation of $\mathrm{PrP}^{\mathrm{Sc}}$ in $\mathrm{ScN} 2 \mathrm{a}$ cell cultures. The percentage of cells having characteristic fibrils on their surface increased with time after scrapie infection. These endogeneous fibrils had lengths from 0.5 to $3 \mu \mathrm{m}$ and protruded from the cell surface by $108 \pm 30 \mathrm{~nm}$, and thus resembled the heterogeneous shapes and networks of in vitro prepared amyloid fibrils.
\end{abstract}

Keywords Atomic force microscopy . Immunofluorescence - Mouse neuroblastoma (N2a) cells . Prion protein $\cdot$ Scrapie $\cdot$ Fibrils $\cdot$ Amyloid

\footnotetext{
S. Wegmann · D. J. Muller $(\bowtie)$

Center of Biotechnology, University of Technology,

Dresden, Germany

e-mail: mueller@biotec.tu-dresden.de

M. Miesbauer $\cdot$ K. F. Winklhofer $\cdot$ J. Tatzelt

Adolf-Butenandt-Institute, Ludwig-Maximilians-University,

Munich, Germany
}

\author{
Abbreviations \\ AFM atomic force microscopy \\ dpp days post plating \\ GA glutaraldehyde \\ $\mathrm{GdnHCl}$ guanidinium hydrochloride \\ GPI glycosylphosphatidylinositol \\ N2a mouse neuroblastoma cell line \\ ScN2a scrapie-infected mouse neuroblastoma cell line \\ PBS phosphate buffered saline \\ PFA paraformaldehyde \\ $\mathrm{PrP} \quad$ prion protein \\ $\mathrm{PrP}^{\mathrm{C}} \quad$ cellular prion protein \\ $\mathrm{PrP}^{\mathrm{Sc}} \quad$ scrapie prion protein \\ $\mathrm{PrP}^{\mathrm{C}+\mathrm{Sc}} \quad$ cellular and scrapie prion protein \\ RML rocky mountain laboratory \\ RMS root mean square \\ $\mathrm{rPrP} \quad$ recombinant prion protein \\ SD standard deviation
}

\section{Introduction}

Prion diseases comprise a group of fatal neurodegenerative diseases in humans and other mammals, which are characterized by the accumulation of abnormally folded prion proteins $(\mathrm{PrP})$, designated $\mathrm{PrP}^{\mathrm{Sc}}$. $\mathrm{PrP}^{\mathrm{Sc}}$, the constituent of infectious prions, is a self-propagating isoform of the cellular prion protein $\left(\mathrm{PrP}^{\mathrm{C}}\right)$ with distinct biochemical and biophysical properties compared to $\operatorname{PrP}^{\mathrm{C}}$ (reviewed in $[1,17,18,54$, 69]). Expression of $\operatorname{PrP}^{\mathrm{C}}$ is essential for the pathogenesis of prion diseases; knock-out mice with a targeted disruption of the $\operatorname{PrP}$ gene are resistant to prion diseases and propagate neither $\operatorname{PrP}^{\mathrm{Sc}}$ nor infectious prions [14]. The biogenesis of $\operatorname{PrP}^{\mathrm{C}}$ is characterized by a series of co- and post-translation 
modifications (reviewed in [66]). In the endoplasmic reticulum, two N-linked glycans (to Asn180 and Asn196 in murine PrP, to Asn181 and Asn197 in human and Syrian hamster PrP) [28] and a C-terminal glycosylphosphatidylinositol (GPI) anchor [60] are added. During transit through the secretory pathway, the glycans are processed into complex structures $[22,56,61]$, and, finally, $\operatorname{PrP}^{\mathrm{C}}$ is targeted to the outer leaflet of the plasma membrane. $\operatorname{PrP}^{\mathrm{Sc}}$, purified from scrapie-infected brains, contains a GPI anchor and sialylated complex N-linked glycans [22, 60], indicating that fully matured $\operatorname{PrP}^{\mathrm{C}}$ is the precursor for the formation of $\operatorname{PrP}^{\mathrm{Sc}}$.

To address questions concerning prion infectivity, the cell toxicity of prions, and disease propagation, stableinfected cell lines permanently expressing high amounts of $\operatorname{PrP}^{\mathrm{Sc}}$ have been established [13, 59]. Although many cell lines express $\operatorname{PrP}^{\mathrm{C}}$, mouse neuroblastoma (N2a) cells belong to a small group of cell lines susceptible to infection with scrapie-prions and, thus, represent a preferred cell culture model $[12,15,16]$. Interestingly, scrapie-infected (Sc)N2a cells continuously propagate protease K-resistant $\mathrm{PrP}^{\mathrm{Sc}}$ and infectious prions, yet, do not show any growth defects compared to uninfected cells. This cell culture model showed that both protein isoforms, $\operatorname{PrP}^{\mathrm{C}}$ and $\mathrm{PrP}^{\mathrm{Sc}}$, are found in detergent-insoluble microdomains (rafts) at the plasma membrane [46, 68]. Based on these and other findings, it appears that $\mathrm{PrP}^{\mathrm{Sc}}$ formation and accumulation occur extracellularly and/or in compartments of the endocytic/lysosomal pathway and depend on the lipid composition of the membrane (reviewed in [49]).

$\mathrm{PrP}^{\mathrm{Sc}}$ has distinct biochemical features, such as insolubility in detergent and a partial resistance to proteolytic digestion [53]. In vitro studies using purified $\mathrm{PrP}^{\mathrm{Sc}}$ demonstrate the self-assembly of $\operatorname{PrP}^{\mathrm{Sc}}$ into oligomers and amyloid fibrils [10, 41]. Such PrP assemblies are routinely analyzed, with regard to fibril growth and structure, using circular dichroism [32, 38], Fourier transform infrared spectroscopy [30, 34], electron microscopy [43, 45, 70], and thioflavine assays [5]. However, between these, in vitro results and the observation of in vivo-occurring amyloid plaques in prion diseases $[1,53]$ remains a large pool of uncertainties about native PrP amyloid formation. Atomic force microscopy (AFM) reveals the topography of cells by a raster scanning the cell surface with a sharp probe [9]. The probe consists of a silicon nitride stylus, typically exhibiting a radius of 10 to $50 \mathrm{~nm}$ at its apex, mounted to the end of a small cantilever. In the contact mode, AFM scans the stylus across the cell surface while maintaining the deflection of the cantilever constant by controlling the height of the cantilever. This procedure reveals the height of the sample for every scanned pixel. Thus, raster scanning the cell surface line by line provides the three-dimensional topography of the cell. Of importance for biological applications, AFM allows imaging in physiological relevant buffer solutions and at ambient temperatures. This avoids dehydration artifacts [21]. The signal to noise ratio of AFM is superior to any optical microscopy technique, and imaging does not require labeling or staining of the sample. With limited sample preparation, cells can be imaged directly by AFM to a vertical resolution of $\sim 5 \mathrm{~nm}$ and a lateral resolution ranging between 20 and $100 \mathrm{~nm}$. Since AFM contrasts topographic features of a cell surface, its combination with light microscopy and specific fluorescence labeling of cellular structures is advantageous [24, 31, 51]. While fluorescence microscopy facilitates the identification of cellular structures, the higher resolution provided by AFM allows the structures to be observed in greater detail. In this work, we used both light microscopy and AFM to characterize surface structures exposed on scrapie-infected cells. The AFM topographs provide information about the structural organization of filaments deposited at the cell surface upon scrapie infection.

\section{Materials and methods}

\section{Cell culture and sample preparation}

N2a cells are immortalized murine neuroblastoma cell lines (ATCC No. CCL 131). ScN2a cells were established by infecting $\mathrm{N} 2 \mathrm{a}$ cells with an enriched preparation of prions isolated from the brains of mice infected with rocky mountain laboratory (RML) prions as described [71]. Both cell lines were cultivated in minimum essential medium with Earle's salts (GIBCO), supplemented with $10 \%$ fetal bovine serum, 100 units $/ \mathrm{mL}$ penicillin, and $100 \mathrm{mg} / \mathrm{mL}$ streptomycin in $5 \% \mathrm{CO}_{2}$ at $37^{\circ} \mathrm{C}$. For AFM and immunofluorescence, cells were grown on glass coverslips for 1 to 6 days. For Western blot analysis, cells were grown in parallel and analyzed using the detergent solubility assay.

\section{Cell fixation for AFM and immunofluorescence microscopy}

For AFM, cells were washed with phosphate buffered saline (PBS) and fixed with $0.2 \%$ glutaraldehyde (GA)/PBS for $45 \mathrm{~s}$ followed by $4 \%$ paraformaldehyde (PFA)/PBS for $20 \mathrm{~min}$. This ensured a high stiffness of the organic material leading to a good resolution in the subsequent AFM scans. To reduce the autofluorescence background in immunofluorescence microscopy, cells were fixed using only the $4 \%$ PFA/PBS treatment for $20 \mathrm{~min}$.

Detergent solubility assay and Western blot analysis

As described previously [64], cells were washed twice with cold PBS, scraped off the plate, pelleted by centrifugation, 
and lysed in cold buffer A $(0.5 \%$ Triton X-100 and $0.5 \%$ sodium deoxycholate in PBS). The lysate was centrifuged at $15,000 \times \mathrm{g}$ for $20 \mathrm{~min}$ at $4^{\circ} \mathrm{C}$ to separate the detergent-soluble (S) from the detergent-insoluble $(\mathrm{P})$ fraction, and PrP was detected by Western blotting as described earlier [71] using the polyclonal anti-PrP antibody pAb A7 [72]. Loading was controlled using the anti- $\alpha$-tubulin antibody (Amersham).

\section{Immunofluorescence microscopy}

$\mathrm{N} 2 \mathrm{a}$ and $\mathrm{ScN} 2 \mathrm{a}$ cells plated on glass coverslips were fixed using 4\% PFA/PBS (for details see "Cell culture and sample preparation"), washed with PBS, and then incubated for $20 \mathrm{~min}$ in $4 \mathrm{M}$ guanidinium hydrochloride $(\mathrm{GdnHCl}) /$ PBS for antigen retrieval. After washing with PBS and blocking for $1 \mathrm{~h}$ with $0.5 \%$ goat serum/PBS (SigmaAldrich), the polyclonal anti-PrP antibody pAb A7 [72] was applied for $2 \mathrm{~h}$ at room temperature. For $\beta$-tubulin counter staining, cells were subsequently permeabilized for $3 \mathrm{~min}$ in $0.4 \%$ Triton X-100/PBS, blocked as before, and incubated in monoclonal mouse anti- $\beta$-tubulin antibody (Sigma-Aldrich) diluted $1: 1,000$ in $0.5 \%$ goat serum/PBS. First, antibody recognition was done by FITC-labeled monoclonal goat anti-rabbit-IgG (Jackson ImmunoResearch) and tritc-labeled monoclonal goat anti-mouse-IgG (Jackson ImmunoResearch), respectively, both diluted $1: 1,000$ in $0.5 \%$ goat serum/PBS. Fluorescence images were taken with a Zeiss Axiovert 200 microscope (Carl Zeiss, Goettingen, Germany). Phase contrast and fluorescence microscopy images were taken using a CoolSNAPcf camera (Photometrics) and processed using MetaMorph software (Universal Imaging Corporation).

\section{AFM}

Coverslips with cultured cells were rinsed with PBS, fixed with $0.2 \% \mathrm{GA} / \mathrm{PBS}$ and $4 \%$ paraformaldehyde/PBS (details in "Cell culture and sample preparation"), and mounted onto the AFM (Nanowizard ${ }^{\mathrm{TM}}$, JPK Instruments) using a sample holder (Biocell ${ }^{\mathrm{TM}}$, JPK Instruments). The AFM was mounted onto a Zeiss Axiovert 200. Contact mode imaging was performed in PBS at room temperature $\left(\sim 23^{\circ} \mathrm{C}\right)$ using non-sharpened V-shaped cantilevers (MLCT, Veeco Instruments, Santa Barbara, CA, USA) with nominal spring constants of 0.01 to $0.03 \mathrm{~N} / \mathrm{m}$. The force applied to the cantilever was set to $\sim 100 \mathrm{pN}$, while feedback gains were manually adjusted to obtain the best resolution in both height and deflection channels. Images were collected at line-scan rates ranging from 0.1 to $0.5 \mathrm{~Hz}$. AFM images were processed and analyzed using the JPK image processing software. The cell surface roughness was determined by selecting $4 \times 4 \mu \mathrm{m}^{2}$ areas of the topographs and calculating the root mean square (RMS) of the mean height value. Topographic cross sections of single filaments were generated using ImageJ and IGOR Pro (WaveMetrics Inc.)

\section{Results}

For our studies, we have chosen N2a cells and their scrapieinfected counterpart $(\mathrm{ScN} 2 \mathrm{a})$ representing $\mathrm{N} 2 \mathrm{a}$ cells infected with RML prions from brains of scrapie-ill mice [71]. The ScN2a cell culture model is commonly used to examine biogenesis of $\operatorname{PrP}^{\mathrm{C}}$ and propagation of $\mathrm{PrP}^{\mathrm{Sc}}$ [59]. Compared to uninfected N2a cells, ScN2a cells show changes in the levels of several mRNAs [26], in the maturation of insulin receptors [48], and in the expression of proteins relevant to cellular iron metabolism [23]. Although intra- and extracellular accumulation of $\operatorname{PrP}^{\mathrm{Sc}}$ is prominent in $\mathrm{ScN} 2 \mathrm{a}$ cells, no differences in cell mortality and apoptosis rates have been found [13]. Herein, we characterized this well-studied cellular model system by AFM to screen for morphological changes and extracellular accumulation of $\mathrm{PrP}^{\mathrm{Sc}}$ upon scrapie infection.

Fibrillar networks form on top of murine neuroblastoma cells after scrapie infection

Light microscopy phase contrast images (Fig. 1a) revealed no structural differences between control (N2a) and scrapieinfected $(\mathrm{ScN} 2 \mathrm{a})$ murine neuroblastoma cells. This is in agreement with a previously published study which indicated that the proliferation rates of $\mathrm{N} 2 \mathrm{a}$ and $\mathrm{ScN} 2 \mathrm{a}$ cells are similar [13]. Earlier, fluorescence microscopy images of immunofluorescent labeled $\operatorname{PrP}^{\mathrm{C}}$ and $\operatorname{PrP}^{\mathrm{Sc}}$ revealed clear differences in the PrP distribution of control and scrapie-infected cells [63]. To further characterize structural details and changes induced by scrapie infection, we investigated $\mathrm{N} 2 \mathrm{a}$ and $\mathrm{ScN} 2 \mathrm{a}$ cells using a combination of phase contrast, fluorescence, and atomic force microscopy.

Initially, we labeled the cell surface PrP of both cell lines using the polyclonal PrP pAb A7 antibody [71]. Next, we permeabilized the cell membrane using Triton X-100 and immunolabeled intracellular $\beta$-tubulin. Using the immunofluorescence of tubulin as a reference signal allowed us to estimate the ratio of infected vs uninfected cells. As expected, N2a cells showed a homogenous distribution of PrP, while in most ScN2a cells, labeled PrP accumulated in restricted areas (Fig. 1a). These results are in agreement with previous studies [63].

To see whether this apparent clustering of $\operatorname{PrP}$ was accompanied by structural changes to the cell surface, we investigated the cells using AFM. AFM deflection images and height topographs of paraformaldehyde- and glutaraldehyde-fixed monolayers of N2a cells (Fig. 1b-c) showed 
smooth surfaces lacking any characteristic features. The average roughness of these cells was $73 \pm 14 \mathrm{~nm}$ (mean $\mathrm{RMS} \pm \mathrm{SD} ; n=16$ ). In contrast, $\mathrm{ScN} 2 \mathrm{a}$ cell layers that have been cultivated for 5 to 6 days under identical conditions were covered by networks of fibrillar structures (Fig. 1de). These networks could extend over several ScN2a cells covering up to $\sim 100 \mu \mathrm{m}^{2}$ of the cell monolayer and differed in thickness, in fibril length, and in the degree of branching. Consequently, the ScN2a cells showed an increased average surface roughness of $104 \pm 28 \mathrm{~nm}$ (mean $\mathrm{RMS} \pm \mathrm{SD} ; n=18)$.

Repeated imaging of the same cell surface area in different scanning directions did not change the structural appearance of single fibrils or the fibrillar network (data not shown). Hence, the possibility that the structures were created or modified by the AFM imaging process can be
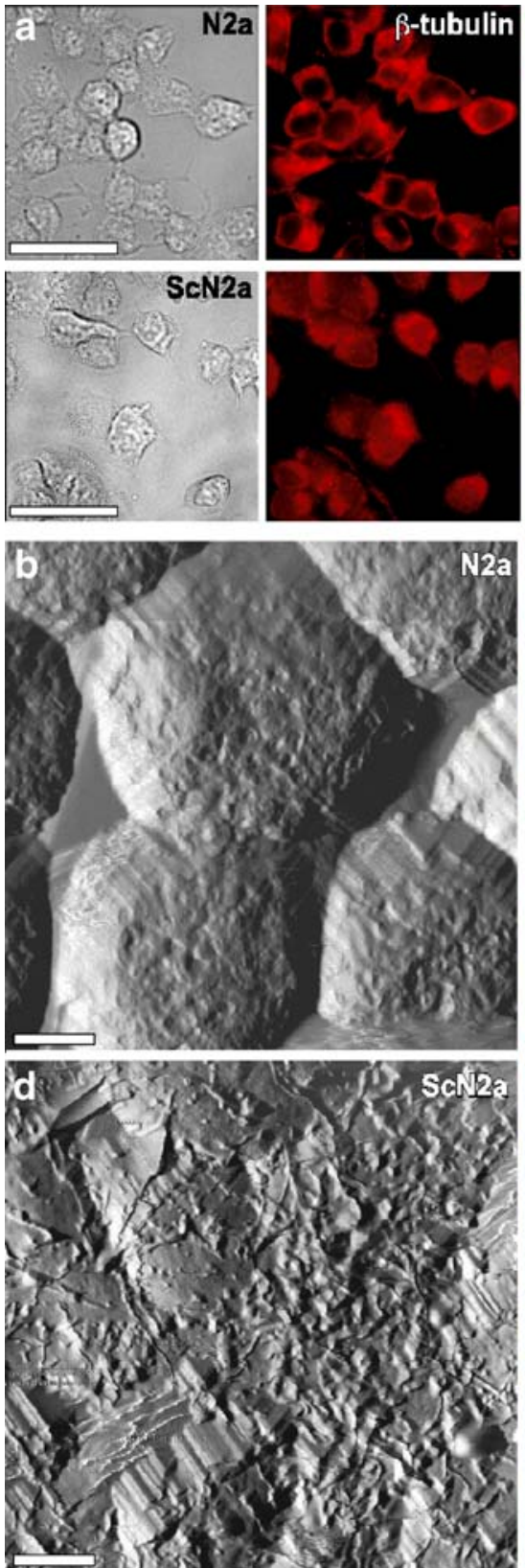

Fig. 1 Light and AFM images of control (N2a) and scrapieinfected $(\mathrm{ScN} 2 \mathrm{a})$ murine neuroblastoma cells. a Phase contrast and fluorescence images show $\beta$-tubulin (red, using monoclonal anti- $\beta$ tubulin antibody) and $\operatorname{PrP}^{\mathrm{C}+\mathrm{Sc}}$ (green, using $\operatorname{PrP}$ antibody pAb A7) in fixed cells. Whereas all N2a cells show a homogenous distribution of surface PrP, some scrapie-infected cells (ScN2a) show PrP
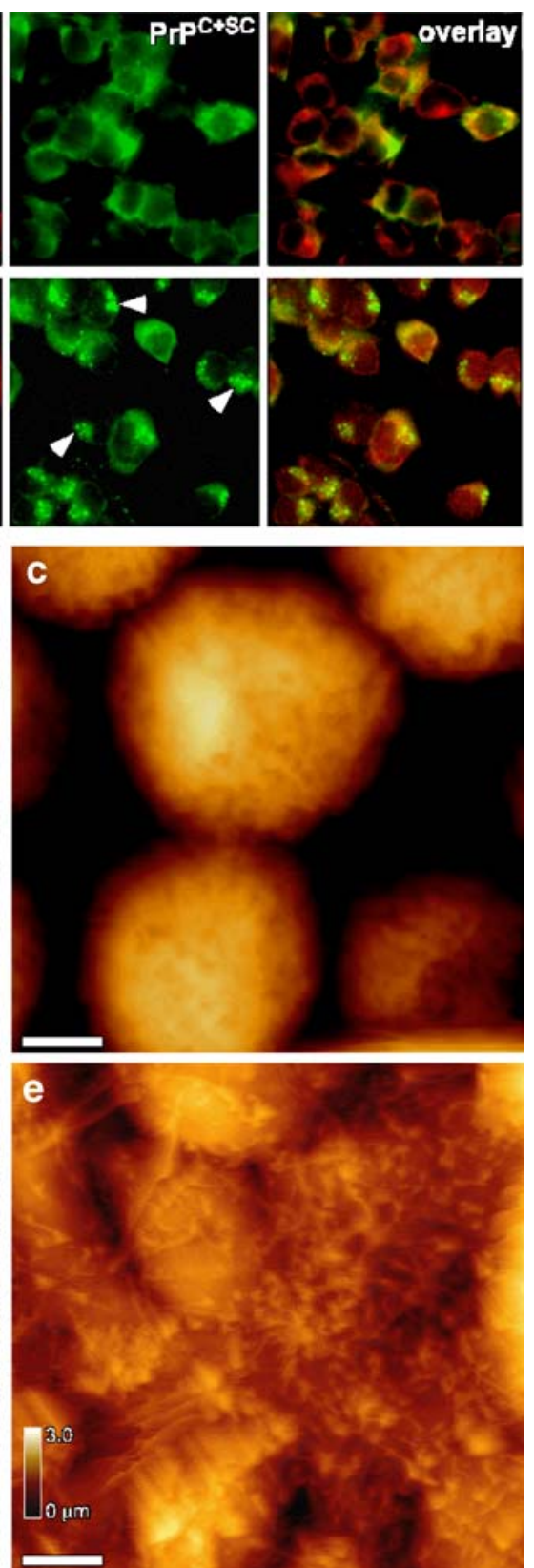

clusters (arrow heads). AFM deflection images (b and d) and topographs (c and e) reveal no major surface structures on N2a cells (b and c) but extensive fibrillar networks on $\mathrm{ScN} 2 \mathrm{a}$ cells (d and e). Scale bars correspond to $50 \mu \mathrm{m}$ (a) and $5 \mu \mathrm{m}$ (b to d). Full color range of AFM topographs (c and e) correspond to a vertical height of $3 \mu \mathrm{m}$ 
excluded. Glutaraldehyde fixation of MDCK cells results in fixation artifacts in the form of small spherical structures on the cell surface [29]. Such artificial structures would alter the surface appearance and roughness of both N2a and $\mathrm{ScN} 2 \mathrm{a}$ cells. Thus, we exclude the possibility that the fibrillar structures, found only on ScN2a cell surfaces, reflect artifacts of fixation or AFM imaging processes.

Unfortunately, we were unable to directly correlate the fibrillar structures observed by AFM with immunofluorescently labeled $\operatorname{PrP}^{\mathrm{Sc}}$. After exposure to $4 \mathrm{M} \mathrm{GdnHCl}$, as required for immunolabeling of $\operatorname{PrP}^{\mathrm{Sc}}$ [63], the ScN2a cell surfaces appeared very compliant. Even at the smallest possible imaging force $(<50 \mathrm{pN})$, AFM images showed the bending of surface structures in the scanning direction. AFM topographs of $\mathrm{GdnHCl}$ treated cell surfaces showed an increased surface roughness, but they were marred by AFM tip contamination and scanning artifacts (data not shown). Artifacts may have been caused by loosely bound cell material $[57,67]$ and could be reduced neither by changing from AFM contact mode to oscillation mode imaging nor by using different AFM tip geometries and materials. Thus, the simultaneous visualization of cell surfaces by fluorescence microscopy and AFM was impeded by the rather harsh chemical treatment required to label $\operatorname{PrP}^{\mathrm{Sc}}$.

$\mathrm{PrP}^{\mathrm{Sc}}$ formation and growth of fibrillar cell surface structures depend on time

Next, we investigated the time dependency of $\mathrm{PrP}^{\mathrm{Sc}}$ formation in scrapie-infected cells by comparing biochemical, immunofluorescence, and AFM data of ScN2a cell cultures at different days post plating (dpp). The overall content of cellular $\operatorname{PrP}^{\mathrm{C}}$ and scrapie-associated $\mathrm{PrP}^{\mathrm{Sc}}$ was determined by solubility assays [64] and subsequent Western blotting (Fig. 2). The amount of tubulin in each sample was used to demonstrate equal protein loading. In $\mathrm{ScN} 2 \mathrm{a}$ cells, the amounts of both $\operatorname{PrP}^{\mathrm{C}}$ in the soluble (S) and $\mathrm{PrP}^{\mathrm{Sc}}$ in the insoluble $(\mathrm{P})$ cellular fractions both increased with cultivation time until the maximum was reached at $4 \mathrm{dpp}$. Longer cultivation, past $4 \mathrm{dpp}$, did not further enhance the amount of PrP. As expected, uninfected N2a cells did not contain any insoluble $\operatorname{PrP}^{\mathrm{Sc}}$ (Fig. 2) and expressed equal amounts of $\mathrm{PrP}^{\mathrm{C}}$ in the time range from 1 to $6 \mathrm{dpp}$ (data not shown). These results matched recently reported PrP amounts in dividing N2a and ScN2a cells [25].

For immunofluorescence microscopy and AFM, infected cell cultures were fixed after 1, 2, 4, and $5 \mathrm{dpp}$. As expected, phase contrast images showed no morphological changes in ScN2a (Fig. 3a). The corresponding immunofluorescence images (Fig. 3b) revealed that the homogeneous surface distribution of PrP observed after 1 and 2 dpp changed at day 4 . At 4 dpp, ScN2a cells showed clustered PrP, which were slightly more condensed at 5 dpp (arrows). Longer cultivation times could not be examined, because after $6 \mathrm{dpp}$, the cultivated cells began to detach from the supporting surface. AFM images of ScN2a cell monolayers (Fig. 3c) and single cells (Fig. 3d) revealed changes in cell surface morphology that increased with dpp. In freshly plated ScN2a samples (1 dpp), single cells were separated well and showed smooth surfaces similar to those of uninfected N2a cells (Figs. 1b-c and 4a). Minor differences in the cell surface appearance observed at $1 \mathrm{dpp}$ may be attributed to variations in cell cycle stage, protein expression levels, and metabolism of individual cells $[55,58]$. After $2 \mathrm{dpp}$, most of the ScN2a cells exposed a slightly increased surface roughness (Fig. 3d, 2 dpp), and individual cells exhibited spherical protrusions and short fibrillar structures (Fig. 3c, 2 dpp). After 4 days of cultivation, most cells were covered by fibrillar structures of increased lengths and widths (Fig. 3c and d). Again, single cells deviated from this appearance,

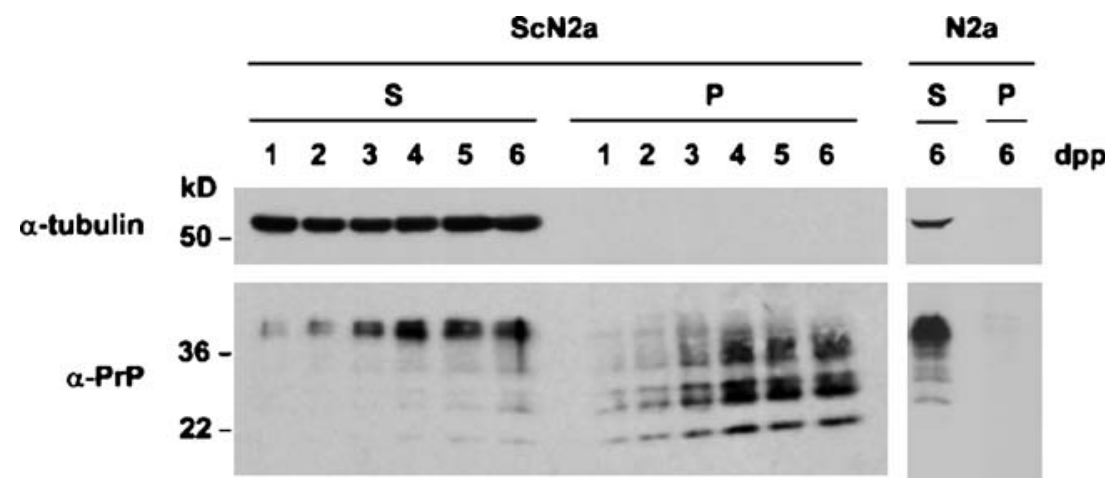

Fig. 2 PrP expression in $\mathrm{ScN} 2 \mathrm{a}$ and $\mathrm{N} 2 \mathrm{a}$. ScN2a cells were harvested, lysed, and fractionated by centrifugation at 1 to 6 days after cell plating (dpp). N2a control cells (6 dpp) were treated in the same way. Endogenous PrP, present in the detergent-soluble (S) and detergentinsoluble $(\mathrm{P})$ cellular fractions, was detected by Western blotting using the PrP antibody pAb A7. To control for equal protein loading, tubulin was detected using an anti- $\alpha$-tubulin antibody. Whereas the Triton $\mathrm{X}$ 100 soluble $\operatorname{PrP}^{\mathrm{C}}$ was detected in the soluble (S) fraction of the cells, $\mathrm{PrP}^{\mathrm{Sc}}$ species remained in the detergent-insoluble $(\mathrm{P})$ fraction 
Fig. 3 Time course of $\mathrm{PrP}^{\mathrm{Sc}}$ formation in $\mathrm{ScN} 2 \mathrm{a}$ cells. a immunofluorescence detection of surface $\mathrm{PrP}^{\mathrm{C}+\mathrm{Sc}}$ were performed on $\mathrm{ScN} 2 \mathrm{a}$ cells at 1,2, 4, and 5 days after plating (dpp). c and $\mathbf{d}$ AFM deflection images of co-cultured ScN2a cells fixed at indicated times. The homogenous distribution of cell surface $\mathrm{PrP}^{\mathrm{C}+\mathrm{Sc}}(\mathbf{b})$, as observed 1 and 2 days after plating, changed on day 4, when the PrP signal started to appear speckled on some cells (white arrow heads in b). AFM deflection images of $\mathrm{ScN} 2 \mathrm{a}$ cells (c and $\mathbf{d}$ ) revealed smooth cell surfaces at days 1 and 2. After 4 days, the surface morphology changed, and fibrillar structures appeared. Scale bars correspond to $20 \mu \mathrm{m}$ (a and b), $5 \mu \mathrm{m}$ (c), and $1 \mu \mathrm{m}$ (d) Phase contrast microscopy and $\mathbf{b}$
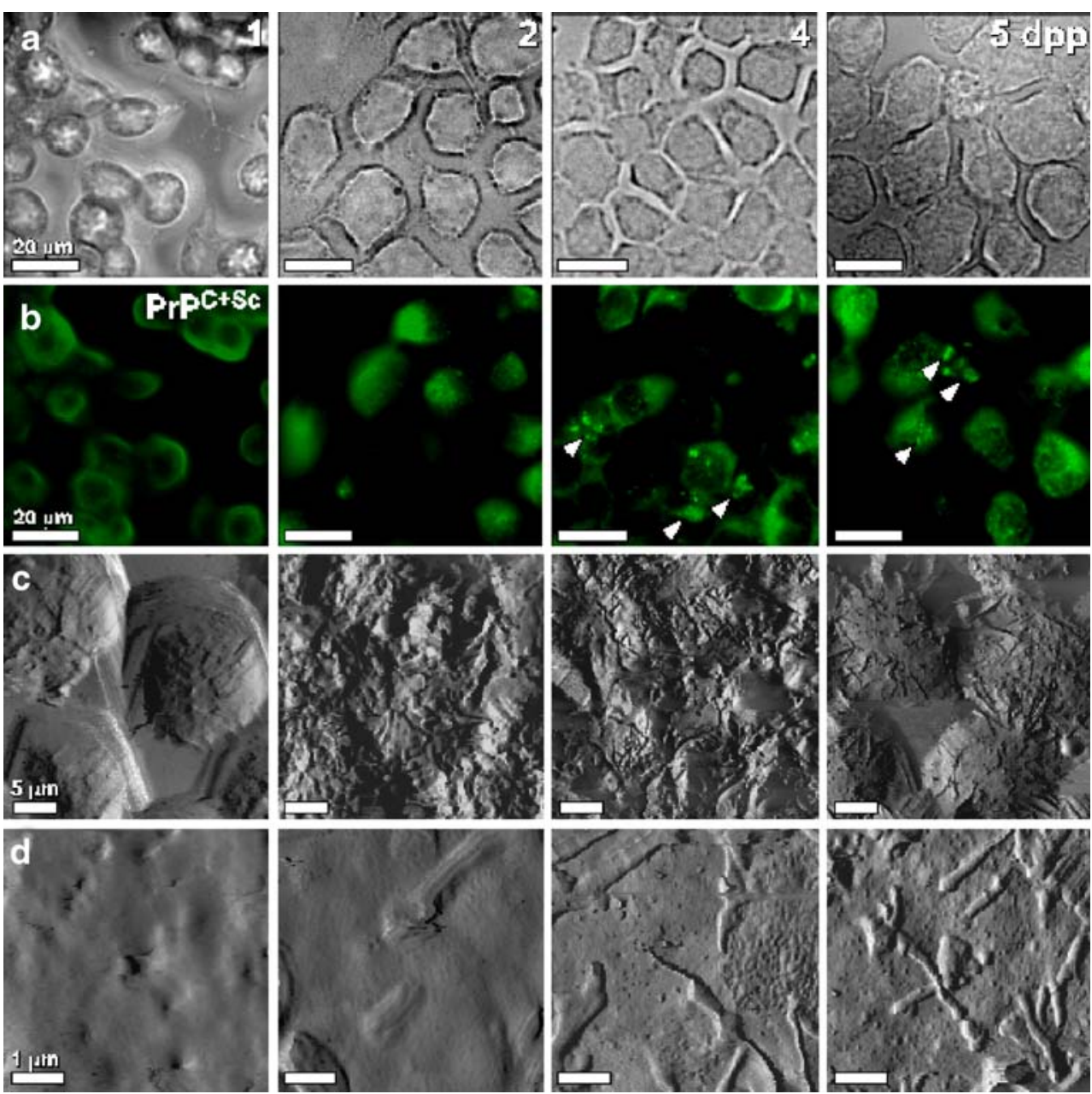

indicating heterogeneity in the manifestation of surface aggregates. The average fibril length and the complexity of the fibril networks increased with cultivation time. Five days after plating, the protruding fibrillar structures on the cell surfaces were more pronounced. Additionally, isolated fibrils were found more frequently (Fig. 3d, 5 dpp), and cross-linked structures appeared to be less spread and more restricted to some areas (Fig. $3 \mathrm{c}, 5 \mathrm{dpp}$ ). In contrast to infected cells, uninfected N2a cells did not morphologically change with either cultivation time or culture confluence (data not shown). Consequently, N2a cells imaged after 5 and 6 dpp, shown in Figs. 1b-c and 4a, are representative for all $\mathrm{N} 2 \mathrm{a}$ cells.

AFM topographs highlight surface differences of scrapie-infected N2a cells

To compare the surface structures of $\mathrm{N} 2 \mathrm{a}$ and $\mathrm{ScN} 2 \mathrm{a}$ cells in greater detail, we recorded AFM images of the top of single cells at higher resolution (Fig. 4a-c). All images were taken at 5 and $6 \mathrm{dpp}$. N2a cells showed smooth cell membrane surfaces exposing small spikes (Fig. 4a, arrows in top image), with an average height of $107 \pm 53 \mathrm{~nm}$ (mean \pm
$\mathrm{SD}, n=26$ ). Similar dimensions were previously observed for microvilli on MDCK cell surfaces [29, 50]. N2a cell surfaces resembled landscapes of smooth hills and valleys, although single N2a cells showed minor variations (Fig. 4a, middle and bottom images). In contrast, the increased roughness of ScN2a cell surfaces (Fig. 4b-c) was caused by numerous, sharply contrasted structures protruding from the smooth cell surface. Most of these protrusions had fibrillar shapes. The cell surface background looked alike that of N2a cells (Fig. 4a). The fibrillar structures differed in length and width but exhibited little variance in height (Fig. 4d-e). Their average protruding height above the cell surface was $108 \pm 30 \mathrm{~nm}$ (mean $\pm \mathrm{SD}, n=60)$, while their average length was $1.0 \pm 0.6 \mu \mathrm{m}($ mean $\pm \mathrm{SD}, n=35)$.

\section{Discussion}

Fibrillar networks covering scrapie-infected cells result

While N2a cells showed a smooth surface lacking any pronounced structural features, $\mathrm{ScN} 2 \mathrm{a}$ cultures showed from $\operatorname{PrP}^{\mathrm{Sc}}$ aggregation 
Fig. 4 Fibrillar surface structures on scrapie-infected $\mathrm{ScN} 2 \mathrm{a}$ cells. A selection of AFM deflection images (a and $\mathbf{b}$ ) and topographs (c) derived from N2a and $\mathrm{ScN} 2 \mathrm{a}$ cells at 5 to 6 days after plating. Deflection images showed feature-less surfaces of non-infected N2a cells (a). Fibrillar structures and networks were found on infected $\mathrm{ScN} 2 \mathrm{a}$ cells (b and c). While AFM deflection images (b) reveal a better contrast, topographs (c) map the height cell surface corrugation. The full color range of all AFM topographs corresponds to vertical height scale of $600 \mathrm{~nm}$. d Cross sections of fibrils taken from AFM topographs as indicated (c). e Histograms show the protruding height and fibril length distributions of isolated fibrils observed on $\mathrm{ScN} 2 \mathrm{a}$ cell surfaces, as measured from fibril cross sections
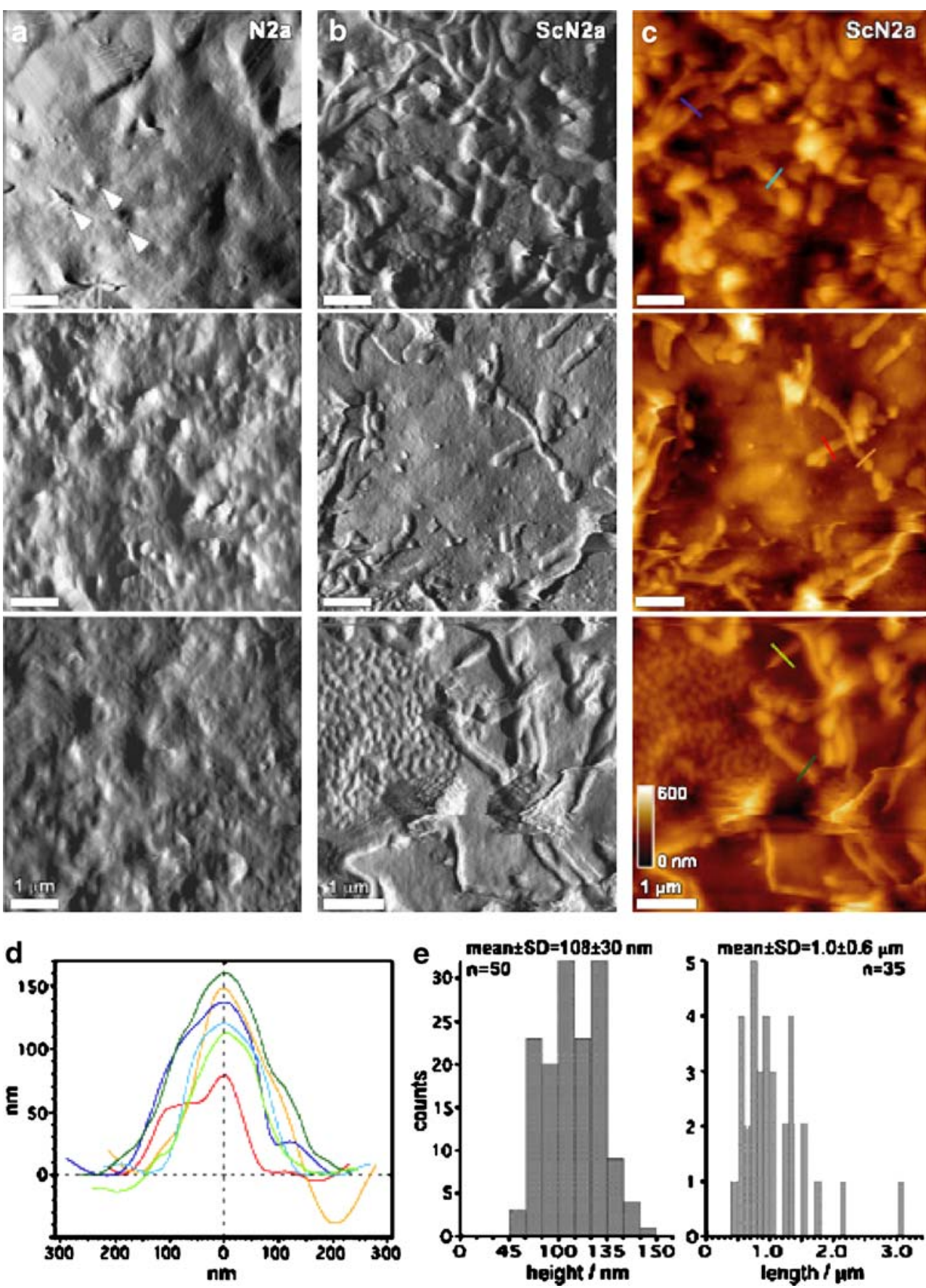

rough and patchy fibrillar networks and exhibited a greater surface roughness. Since N2a and ScN2a cells almost exclusively differ in the high amounts of scrapie protein accumulated by ScN2a cells [15], we link the observed morphological changes to this protein. Our AFM topographs revealed that the fibrillar structures, found on $\mathrm{ScN} 2 \mathrm{a}$ cells after 5-6 days of cultivation, protruded from the cell surface by $\sim 100 \mathrm{~nm}$. This height is in agreement with the dimensions obtained by transmission electron microscopy of in vitro assembled amyloid bundles (50-250 nm; [33]). In vitro assembled solitary recombinant mouse prion protein
$(\mathrm{rPrP})$ fibrils exhibit a wide range of lengths from $\leq 0.25$ to $4 \mu \mathrm{m}$ [6], which increases with assembling time and mechanical breakage of PrP fibrils [62]. Again, these values agree with the wide fibril length distribution and the average length of $\sim 1.0 \mu \mathrm{m}$ we observed. Lateral fibril annealing [2] or other physical rearrangements of the fibrils during growth and aggregation on the cell surface [7] may also have contributed to the heterogeneity of fibril length and height in the AFM topographs.

Beyond the dimensions of single fibrils, the structure and extension of the observed fibrillar networks resembled that 
of scrapie-associated fibrils (SAF), which had been either assembled in vitro from recombinant $\operatorname{PrP}[10,52]$ or extracted from solubilized and proteinase K-digested brain homogenates of scrapie-infected animals [19, 20, 43, 44]. However, so far, $\mathrm{PrP}^{\mathrm{Sc}}$-containing fibrils have not been found in infected brain tissues. The brain derived SAFs may assemble during homogenization or extraction and, thus, be preparation artifacts $[42,65]$. To our knowledge, the AFM images presented in this work are the first microscopy images reporting amyloid-like fibrillar structures on the surface of scrapie-infected cultured cells. However, the observed structures may also result from the cellular response to the scrapie infection, e.g. changes in membrane composition or enhanced dendrite outgrowth.

Heterogeneity of ScN2a cell surfaces structures

Our AFM data showed a variety of surface features on scrapie-infected cells, ranging from single isolated protrusions to fibrils of different lengths and large amorphous aggregates. This heterogeneity of structures is in agreement with the assembling of diverse amyloid aggregates upon incubation of PrP fibrils in cell culture medium both in the absence and presence of cells [10, 47]. Furthermore, assembling states and final structure of in vitro assembled oligomers and short uniform fibrils of $\mathrm{rPrP}$ were shown to depend on $\mathrm{pH}$, temperature, and electrolyte $[4,11,33]$, as well as on the presence of the denaturants $\mathrm{GdnHCl}$ and urea $[10,47]$. Previous AFM studies of PrP fibrils revealed specific structural characteristics for different prion strains $[2,30]$. Thus, the diversity in structures on $\mathrm{ScN} 2 \mathrm{a}$ cells can be accredited to multiple cellular and environmental conditions in the cell culture.

Local restriction of fibrillar structures follows heterogeneous $\mathrm{PrP}^{\mathrm{Sc}}$ accumulation

Scrapie-infected cell cultures showed a heterogeneous distribution of patch-like fibrillar networks, and immunofluorescence images of infected cells (Fig. 1a and 3) showed that not every cell exhibited speckled PrP clusters indicative of $\operatorname{PrP}^{\mathrm{Sc}}$ formation. It remains unclear whether cells, lacking fibrillar surface structures or clustered PrP signals, were uninfected, or whether they did not have the sufficient amount of $\operatorname{PrP}^{\mathrm{Sc}}$ to cause these signs of infection. Heterogeneous distribution of $\operatorname{PrP}^{\mathrm{Sc}}$ formation in cultures of ScN2a cells was shown by Klohn et al. [37]. Within one cell culture dish, they found that micro-colonies with high $\mathrm{PrP}^{\mathrm{Sc}}$ levels neighbored uninfected cells. This suggests that the areas of scrapie-infected cell monolayers covered by fibrillar structures coincided with cells exhibiting high $\mathrm{PrP}^{\mathrm{Sc}}$ content. The patch-like appearance of the fibrillar networks can be explained by heterogeneous $\operatorname{PrP}^{\mathrm{Sc}}$ accu- mulation of individual cells or cell groups in the culture dishes leading to locally restricted $\mathrm{PrP}^{\mathrm{Sc}}$ aggregation, fibril growth, and amyloid formation.

The amyloid fibrils may be the result of in situ $\mathrm{PrP}^{\mathrm{Sc}}$ selfassembling or of the deposition of pre-assembled amyloid from solution. Our AFM images of ScN2a cells recorded after different days of cultivation (Fig. 3) point towards a stepwise increase in surface amyloid formation, thereby excluding the deposition of preformed amyloid meshes.

Amyloid formation and $\mathrm{PrP}^{\mathrm{Sc}}$ accumulation are progressive processes

While most ScN2a cells did not reveal any morphological changes within the first 2 days of cultivation, large fibril networks had fully developed on numerous areas of the cell monolayers after 4 days. Longer cultivation times of 5-6 days resulted only in minor rearrangements of amyloid-like fibrils. These structures may reflect different stages in the progressive assembling and maturing process of amyloid fibrils $[4,40]$ on the cell surface. In all the three independently performed assays, Western blot, immunofluorescence, and AFM topographs, the first signs for $\mathrm{PrP}^{\mathrm{Sc}}$ in scrapie-infected cells were detected 4 days after cell plating. The parallel occurrence of $\mathrm{PrP}^{\mathrm{Sc}}$ formation, PrP aggregation, and morphological changes to the cell surface suggests the direct involvement of $\operatorname{PrP}^{\mathrm{Sc}}$ in the progressive growth of amyloidic fibril networks in scrapie-infected cell cultures.

Mice and hamster animal models represent much more complex systems than the herein-studied $\mathrm{ScN} 2 \mathrm{a}$ cell line. Accordingly, incubation times of 7 weeks are required in mice until proteinase K-resistant $\operatorname{PrP}$ is found at brain sites of inoculation with RML prions [65]. Afterwards, a linear increase of $\operatorname{PrP}^{\mathrm{Sc}}$ was observed until 19 weeks post inoculation. Elsewhere, a rise in prion titer was reported to plateau before observing the actual onset of neuropathological changes $[3,8,36]$. In contrast, in vitro PrP fibril formation occurs within a few hours. Such assays represent a crude and oversimplified model for in vivo amyloid formation. However, in vitro studies revealed a strong dependence of the fibril assembly on environmental conditions such as $\mathrm{pH}$, temperature, and electrolytes [4]. In this context, $\mathrm{ScN} 2 \mathrm{a}$ cells reflect a more natural tool to study complex in vivo processes associated with scrapie infection, because they provide a cellular context for $\operatorname{PrP}^{\mathrm{Sc}}$ formation and aggregation. Comparing the complexity and amyloid formation characteristics of the three model systems - in vivo, in vitro, and cell culture - the time scale of days for progressive $\mathrm{PrP}^{\mathrm{Sc}}$ accumulation and fibril formation in $\mathrm{ScN} 2 \mathrm{a}$ cells appears to be reasonable.

The accumulation of $\operatorname{PrP}^{\mathrm{Sc}}$ was shown using the solubility assay of whole cell lysates (Fig. 2), as well as 
by the clustered signals occurring in the immunofluorescence analysis of ScN2a cells (Fig. 3). Although the immunofluorescence labeling of $\mathrm{PrP}^{\mathrm{C}+\mathrm{Sc}}$ was initially performed without permeabilizing the cells, perforation of the cell membrane during $\mathrm{GdnHCl}$ incubation could have provided access for the antibody to intracellular PrP. Therefore, neither of these assays allows for a strict discrimination of extra- and intracellular PrP species. For different disease-associated mutations in the $\operatorname{PrP}^{\mathrm{C}}$ gene, changes in protein trafficking and rerouting lead to cytosolic and endoplasmatic reticulum accumulation of misfolded $\operatorname{PrP}$ in N2a cells [27, 35, 39] (reviewed in [66]). Assuming that $\mathrm{PrP}^{\mathrm{Sc}}$ is processed similar to misfolded $\operatorname{PrP}^{\mathrm{C}}$, the $\operatorname{PrP}^{\mathrm{Sc}}$ signals observed by immunofluorescence may rather result from intracellular aggregates than from extracellular deposits.

\section{Conclusions}

Using AFM, we discovered differences in the cell surface morphology of uninfected and scrapie-infected cells. Cellular formation and accumulation of $\operatorname{PrP}^{\mathrm{Sc}}$ was shown to occur in parallel to fibril formation and growth on the cell surface. Therefore, we conclude that the single and complex branched fibrillar structures found on scrapieinfected cells are $\mathrm{PrP}^{\mathrm{Sc}}$-containing amyloid fibrils. The patch-like appearance of the fibrillar networks can be explained by heterogeneous $\mathrm{PrP}^{\mathrm{Sc}}$ accumulation of individual cells or cell groups in the culture dishes. Consequently, questions regarding the cellular characteristics and environmental conditions that make a cell susceptible to scrapie infection and induce high level $\mathrm{PrP}^{\mathrm{Sc}}$ expression remain to be answered.

Acknowledgements We thank Jonne Helenius and Angelika Rambold for helpful discussions, and Isabel Richter and Eren Yuskel for experimental assistance. This work was supported by the Deutsche Forschungsgemeinschaft (SFB 596, GK 1401/1), the AO-Davos Foundation, and by the Max-Planck-Society.

\section{References}

1. Aguzzi A, Polymenidou M (2004) Mammalian prion biology: one century of evolving concepts. Cell 116:313-327

2. Anderson M, Bocharova OV, Makarava N, Breydo L, Salnikov VV, Baskakov IV (2006) Polymorphism and ultrastructural organization of prion protein amyloid fibrils: an insight from high resolution atomic force microscopy. J Mol Biol 358:580-596

3. Baringer JR, Bowman KA, Prusiner SB (1983) Replication of the scrapie agent in hamster brain precedes neuronal vacuolation. $\mathrm{J}$ Neuropathol Exp Neurol 42:539-547

4. Baskakov IV, Legname G, Baldwin MA, Prusiner SB, Cohen FE (2002) Pathway complexity of prion protein assembly into amyloid. J Biol Chem 277:21140-21148
5. Baskakov IV (2004) Autocatalytic conversion of recombinant prion proteins displays a species barrier. J Biol Chem 279:76717677

6. Baskakov IV, Bocharova OV (2005) In vitro conversion of mammalian prion protein into amyloid fibrils displays unusual features. Biochemistry 44:2339-2348

7. Baskakov IV (2007) Branched chain mechanism of polymerization and ultrastructure of prion protein amyloid fibrils. FEBS J 274:3756-3765

8. Beekes M, Baldauf E, Diringer H (1996) Sequential appearance and accumulation of pathognomonic markers in the central nervous system of hamsters orally infected with scrapie. J Gen Virol 77(Pt 8):1925-1934

9. Binnig G, Quate CF, Gerber C (1986) Atomic force microscope. Phys Rev Lett 56:930-933

10. Bocharova OV, Breydo L, Parfenov AS, Salnikov VV, Baskakov IV (2005) In vitro conversion of full-length mammalian prion protein produces amyloid form with physical properties of $\operatorname{PrP}$ (Sc). J Mol Biol 346:645-659

11. Bocharova OV, Makarava N, Breydo L, Anderson M, Salnikov VV, Baskakov IV (2006) Annealing prion protein amyloid fibrils at high temperature results in extension of a proteinase K-resistant core. J Biol Chem 281:2373-2379

12. Borchelt DR, Taraboulos A, Prusiner SB (1992) Evidence for synthesis of scrapie prion proteins in the endocytic pathway. $\mathrm{J}$ Biol Chem 267:16188-16199

13. Bosque PJ, Prusiner SB (2000) Cultured cell sublines highly susceptible to prion infection. J Virol 74:4377-4386

14. Büeler H, Aguzzi A, Sailer A, Greiner R-A, Autenried P, Aguet M, Weissmann C (1993) Mice devoid of PrP are resistant to scrapie. Cell 73:1339-1347

15. Butler DA, Scott MR, Bockman JM, Borchelt DR, Taraboulos A, Hsiao KK, Kingsbury DT, Prusiner SB (1988) Scrapie-infected murine neuroblastoma cells produce protease-resistant prion proteins. J Virol 62:1558-1564

16. Caughey B, Raymond GJ (1991) The scrapie-associated form of $\mathrm{PrP}$ is made from a cell surface precursor that is both proteaseand phospholipase-sensitive. J Biol Chem 266:18217-18223

17. Chesebro B (2003) Introduction to the transmissible spongiform encephalopathies or prion diseases. Br Med Bull 66:1-20

18. Collinge J (2001) Prion diseases of humans and animals: their causes and molecular basis. Annu Rev Neurosci 24:519-550

19. DeArmond SJ, McKinley MP, Barry RA, Braunfeld MB, McColloch JR, Prusiner SB (1985) Identification of prion amyloid filaments in scrapie-infected brain. Cell 41:221-235

20. Diringer H, Gelderblom H, Hilmert H, Ozel M, Edelbluth C, Kimberlin RH (1983) Scrapie infectivity, fibrils and low molecular weight protein. Nature 306:476-478

21. Drake B, Prater CB, Weisenhorn AL, Gould SA, Albrecht TR, Quate CF, Cannell DS, Hansma HG, Hansma PK (1989) Imaging crystals, polymers, and processes in water with the atomic force microscope. Science 243:1586-1589

22. Endo T, Groth D, Prusiner SB, Kobata A (1989) Diversity of oligosaccharide structures linked to asparagines of the scrapie prion protein. Biochemistry 28:8380-8388

23. Fernaeus S, Halldin J, Bedecs K, Land T (2005) Changed iron regulation in scrapie-infected neuroblastoma cells. Mol Brain Res 133:266-273

24. Franz CM, Muller DJ (2005) Analyzing focal adhesion structure by atomic force microscopy. J Cell Sci 118:5315-5323

25. Ghaemmaghami S, Phuan PW, Perkins B, Ullman J, May BC, Cohen FE, Prusiner SB (2007) From the cover: cell division modulates prion accumulation in cultured cells. Proc Natl Acad Sci USA 104:17971-17976

26. Greenwood AD, Horsch M, Stengel A, Vorberg I, Lutzny G, Maas E, Schadler S, Erfle V, Beckers J, Schatzl H, Leib-Mosch C 
(2005) Cell line dependent RNA expression profiles of prioninfected mouse neuronal cells. J Mol Biol 349:487-500

27. Grenier C, Bissonnette C, Volkov L, Roucou X (2006) Molecular morphology and toxicity of cytoplasmic prion protein aggregates in neuronal and non-neuronal cells. J Neurochem 97:1456-1466

28. Haraguchi T, Fisher S, Olofsson S, Endo T, Groth D, Tarentino A, Borchelt DR, Teplow D, Hood L, Burlingame A, Lycke E, Kobata A, Prusiner SB (1989) Asparagine-linked glycosylation of the scrapie and cellular prion proteins. Arch Biochem Biophys 274:113

29. Hoh J, Schoenenberger C (1994) Surface morphology and mechanical properties of MDCK monolayers by atomic force microscopy. J Cell Sci 107:1105-1114

30. Jones EM, Surewicz WK (2005) Fibril conformation as the basis of species- and strain-dependent seeding specificity of mammalian prion amyloids. Cell 121:63-72

31. Kassies R, van der Werf KO, Lenferink A, Hunter CN, Olsen JD, Subramaniam V, Otto C (2005) Combined AFM and confocal fluorescence microscope for applications in bio-nanotechnology. J Microsc 217:109-116

32. Kazlauskaite J, Sanghera N, Sylvester I, Venien-Bryan C, Pinheiro TJ (2003) Structural changes of the prion protein in lipid membranes leading to aggregation and fibrillization. Biochemistry 42:3295-3304

33. Kazlauskaite J, Pinheiro TJ (2005) Aggregation and fibrillization of prions in lipid membranes. Biochem Soc Symp 72:211-222

34. Kazlauskaite J, Young A, Gardner CE, Macpherson JV, VenienBryan C, Pinheiro TJ (2005) An unusual soluble beta-turn-rich conformation of prion is involved in fibril formation and toxic to neuronal cells. Biochem Biophys Res Commun 328:292-305

35. Kiachopoulos S, Heske J, Tatzelt J, Winklhofer KF (2004) Misfolding of the prion protein at the plasma membrane induces endocytosis, intracellular retention and degradation. Traffic 5:426-436

36. Kimberlin RH, Walker CA (1979) Pathogenesis of mouse scrapie: dynamics of agent replication in spleen, spinal cord and brain after infection by different routes. J Comp Pathol 89:551-562

37. Klohn PC, Stoltze L, Flechsig E, Enari M, Weissmann C (2003) A quantitative, highly sensitive cell-based infectivity assay for mouse scrapie prions. Proc Natl Acad Sci USA 100:11666-11671

38. Luhrs T, Zahn R, Wuthrich K (2006) Amyloid formation by recombinant full-length prion proteins in phospholipid bicelle solutions. J Mol Biol 357:833-841

39. Ma J, Wollmann R, Lindquist S (2002) Neurotoxicity and neurodegeneration when $\operatorname{PrP}$ accumulates in the cytosol. Science 298:1781-1785

40. Makarava N, Bocharova OV, Salnikov VV, Breydo L, Anderson M, Baskakov IV (2006) Dichotomous versus palm-type mechanisms of lateral assembly of amyloid fibrils. Protein Sci 15:13341341

41. Martins SM, Frosoni DJ, Martinez AM, De Felice FG, Ferreira ST (2006) Formation of soluble oligomers and amyloid fibrils with physical properties of the scrapie isoform of the prion protein from the C-terminal domain of recombinant murine prion protein mPrP-(121-231). J Biol Chem 281:26121-26128

42. McKinley MP, Meyer RK, Kenaga L, Rahbar F, Cotter R, Serban A, Prusiner SB (1991) Scrapie prion rod formation in vitro requires both detergent extraction and limited proteolysis. J Virol 65:1340-1351

43. Merz PA, Somerville RA, Wisniewski HM, Iqbal K (1981) Abnormal fibrils from scrapie-infected brain. Acta Neuropathol (Berl) 54:63-74

44. Merz PA, Somerville RA, Wisniewski HM, Manuelidis L, Manuelidis EE (1983) Scrapie-associated fibrils in CreutzfeldtJakob disease. Nature 306:474-476
45. Moore RA, Hayes SF, Fischer ER, Priola SA (2007) Amyloid formation via supramolecular peptide assemblies. Biochemistry 46:7079-7087

46. Naslavsky N, Stein R, Yanai A, Friedlander G, Taraboulos A (1997) Characterization of detergent-insoluble complexes containing the cellular prion protein and its scrapie isoform. J Biol Chem 272:6324-6331

47. Novitskaya V, Bocharova OV, Bronstein I, Baskakov IV (2006) Amyloid fibrils of mammalian prion protein are highly toxic to cultured cells and primary neurons. J Biol Chem 281:1382813836

48. Ostlund P, Lindegren H, Pettersson C, Bedecs K (2001) Altered insulin receptor processing and function in scrapie-infected neuroblastoma cell lines. Mol Brain Res 97:161-170

49. Pinheiro TJ (2006) The role of rafts in the fibrillization and aggregation of prions. Chem Phys Lipids 141:66-71

50. Poole K, Meder D, Simons K, Muller D (2004) The effect of raft lipid depletion on microvilli formation in MDCK cells, visualized by atomic force microscopy. FEBS Lett 565:53-58

51. Poole K, Muller D (2005) Flexible, actin-based ridges colocalise with the betal integrin on the surface of melanoma cells. Br J Cancer 92:1499-1505

52. Prusiner SB, McKinley MP, Bowman KA, Bolton DC, Bendheim PE, Groth DF, Glenner GG (1983) Scrapie prions aggregate to form amyloid-like birefringent rods. Cell 35:349-358

53. Prusiner SB (1998) Prions. Proc Natl Acad Sci USA 95:1336313383

54. Prusiner SB, Scott MR, DeArmond SJ, Cohen FE (1998) Prion protein biology. Cell 93:337-348

55. Rubin RW, Everhart LP (1973) The effect of cell-to-cell contact on the surface morphology of Chinese hamster ovary cells. J Cell Biol 57:837-844

56. Rudd PM, Endo T, Colominas C, Groth D, Wheeler SF, Harvey DJ, Wormald MR, Serban H, Prusiner SB, Kobata A, Dwek RA (1999) Glycosylation differences between the normal and pathogenic prion protein isoforms. Proc Natl Acad Sci USA 96:1304413049

57. Schwarz UD, Haefke H, Reimann P, Guntherodt HJ (1994) Tip artifacts in scanning force microscopy. J Microsc 173:183-197

58. Shay JW, Porter KR, Prescott DM (1974) The surface morphology and fine structure of $\mathrm{CHO}$ (Chinese hamster ovary) cells following enucleation. Proc Natl Acad Sci USA 71:3059-3063

59. Solassol J, Crozet C, Lehmann S (2003) Prion propagation in cultured cells. Br Med Bull 66:87-97

60. Stahl N, Borchelt DR, Hsiao K, Prusiner SB (1987) Scrapie prion protein contains a phosphatidylinositol glycolipid. Cell 51:229 240

61. Stimson E, Hope J, Chong A, Burlingame AL (1999) Site-specific characterization of the $\mathrm{N}$-linked glycans of murine prion protein by high-performance liquid chromatography/electrospray mass spectrometry and exoglycosidase digestions. Biochemistry 38:4885-4895

62. Tanaka M, Collins SR, Toyama BH, Weissman JS (2006) The physical basis of how prion conformations determine strain phenotypes. Nature 442:585-589

63. Taraboulos A, Serban D, Prusiner S (1990) Scrapie prion proteins accumulate in the cytoplasm of persistently infected cultured cells. J Cell Biol 110:2117-2132

64. Tatzelt J, Prusiner SB, Welch WJ (1996) Chemical chaperones interfere with the formation of scrapie prion protein. EMBO J 15:6363-6373

65. Tatzelt J, Groth DF, Torchia M, Prusiner SB, DeArmond SJ (1999) Kinetics of prion protein accumulation in the CNS of mice with experimental scrapie. J Neuropathol Exp Neurol 58:1244 1249 
66. Tatzelt J, Winklhofer KF (2004) Folding and misfolding of the prion protein in the secretory pathway. Amyloid 11:162-172

67. Velegol SB, Pardi S, Li X, Velegol D, Logan BE (2003) AFM imaging artifacts due to bacterial cell height and AFM tip geometry. Langmuir 19:851-857

68. Vey M, Pilkuhn S, Wille H, Nixon R, DeArmond SJ, Smart EJ, Anderson RG, Taraboulos A, Prusiner SB (1996) Subcellular colocalization of the cellular and scrapie prion proteins in caveolaelike membranous domains. Proc Natl Acad Sci USA 93:14945-14949

69. Weissmann C, Fischer M, Raeber A, Büeler H, Sailer A, Shmerling D, Rülicke T, Brandner S, Aguzzi A (1996) The role of PrP in pathogenesis of experimental scrapie. Cold Spring Harb Symp Quant Biol 61:511-522

70. Wille H, Prusiner SB, Cohen FE (2000) Scrapie infectivity is independent of amyloid staining properties of the N-terminally truncated prion protein. J Struct Biol 130:323-338

71. Winklhofer KF, Tatzelt J (2000) Cationic lipopolyamines induce degradation of PrPSc in scrapie-infected mouse neuroblastoma cells. Biol Chem 381:463-469

72. Winklhofer KF, Heller U, Reintjes A, Tatzelt J (2003) Inhibition of complex glycosylation increases the formation of PrPsc. Traffic $4: 313-322$ 